Chapter 2

\title{
Techniques for the Preparation of Solid Lipid Nano and Microparticles
}

\author{
Luigi Battaglia, Marina Gallarate, \\ Pier Paolo Panciani, Elena Ugazio, Simona Sapino, \\ Elena Peira and Daniela Chirio
}

Additional information is available at the end of the chapter

http://dx.doi.org/10.5772/58405

\section{Introduction}

SLN are nanoparticles made of solid lipids with a photon correlation spectroscopy (PCS) mean diameter approximately between 50 and $1000 \mathrm{~nm}$ [1].

General ingredients include solid lipid(s), surfactant(s) and water. The term lipid is used here in a broad sense and includes triglycerides (e.g. tristearin), partial glycerides, fatty acids (e.g. stearic acid), steroids (e.g. cholesterol) and waxes (e.g. cetyl palmitate). All classes of surfactants (with respect to charge and molecular weight) have been used to stabilize the lipid dispersion [2].

SLN were developed in the early 1990s and up today they have been considered to be promising drug carrier systems, especially with the aim to give a sustained release profile to the incorporated active substances. In fact, compared to liquid lipid formulations, such as nanoemulsions, drug mobility is really lower in solid lipids than in liquid oils. Compared to polymeric nanoparticles, they show a better biocompatibility since they're made of lipids similar to physiological one, so the toxicity is reduced. Moreover SLN are physico-chemically stable and can be produced easily on a large industrial scale, and raw material and production costs are relatively low [1].

SLM have equivalent composition to SLN, but higher particle size (>1000 nm), meaning that their application domains and administration routes can be different [3]. 
There are different techniques for the preparation of solid lipid nano-and microparticles: generally, the preparation of nano-and microparticles requires a dispersed system as precursor or template, otherwise particles are produced through the use of a particular instrumentation.

The most important precursor are emulsions (hot homogenisation technique, melt dispersion technique, PIT method, solvent evaporation-diffusion from emulsions), microemulsions (microemulsion dilution and microemulsion cooling techniques), micellar solutions (coacervation technique). Some preparation techniques are based on supercritical fluids. The most important techniques which involve the use of particular instrumentation are: membrane contactor technique, spray-drying, spray-congealing and electrospray.

In Table 1 a scheme of the main preparation techniques of solid lipid nano-and microparticles is reported.

\begin{tabular}{llc}
\hline Precursor system & Technique & Nanoparticle type \\
\hline Emulsion & Hot homogenisation (high pressure & SLN \\
homogenisation, high shear homogenisation, & ultrasound homogenisation) & SLM \\
\hline Emulsion & Melt dispersion & SLN \\
\hline Emulsion & PIT method & SLN \\
\hline Microemulsion & Microemulsion dilution & SLN \\
\hline Microemulsion & Microemulsion cooling & SLN \\
\hline Micellar solution & Coacervation & SLN \\
\hline Organic solvent solution & Solvent injection & SLN \\
\hline Organic solvent emulsion & Solvent evaporation from emulsions & SLN \\
\hline Organic solvent emulsion & Solvent diffusion from emulsions & SLN/SLM \\
\hline Gas-saturated solution/suspension & Particles from gas-saturated solutions/ & SLN \\
\hline Supercritical fluid emulsion & suspensions & SLN \\
\hline & Supercritical fluid extraction of emulsions & SLM \\
\hline & Membrane contactor technique & SLM \\
\hline
\end{tabular}

Table 1. Preparation techniques of solid lipid nano-and microparticles

\section{Emulsion precursors}

The most important precursor used for the preparation of solid lipid particles is the emulsion.

Emulsion consists of a mixture of two immiscible liquids (eg. water - W-and oil-O), where one is dispersed in the other in the form of droplets, thanks to the use of emulsifying agent. 
According to the character of the continuous and dispersed phase, emulsions can be direct $(\mathrm{O} /$ $\mathrm{W})$, reversed $(\mathrm{W} / \mathrm{O})$ and multiple $(\mathrm{W} / \mathrm{O} / \mathrm{W}$ and $\mathrm{O} / \mathrm{W} / \mathrm{O})$.

Emulsions can be used as precursors for solid lipid particles preparation since lipids, that are solid at room temperature, can be heated $5-10{ }^{\circ} \mathrm{C}$ above their melting point to obtain a liquid lipid that can be emulsified with water at the same temperature: the obtained hot emulsion is then cooled to room temperature and the droplets solidify in the form of solid lipid particles.

Owing to the size of the hot emulsion droplets, nano-or microparticles can be obtained.

SLN can be obtained from hot $\mathrm{O} / \mathrm{W}$ nanoemulsion ( $<1 \mu \mathrm{m}$ droplet size), prepared through the so called hot homogenisation technique. Different methods can be used to achieve hot homogenisation: high pressure homogenisation, high shear homogenisation, ultrasound homogenisation.

SLM, instead, can be obtained from hot emulsions ( $>1 \mu \mathrm{m}$ droplet size) by the so called melt dispersion technique: $\mathrm{O} / \mathrm{W}$ or multiple $\mathrm{W} / \mathrm{O} / \mathrm{W}$ precursors can be used.

\subsection{Hot homogenisation}

\subsubsection{High pressure homogenisation}

High pressure homogenisation (HPH) was applied for the first time in the nineties by Müller and Lucks [4] for SLN production and represents the main method established for them.

In the $\mathrm{HPH}$ technique the drug is dissolved in the lipid being melted at approximately $5-10{ }^{\circ} \mathrm{C}$ above its melting point. The drug-containing melt is dispersed under stirring in a hot aqueous surfactant solution of identical temperature, in order to obtain pre-emulsion, which is then homogenised using a piston-gap homogeniser; the produced hot $\mathrm{O} / \mathrm{W}$ nanoemulsion is cooled down to room temperature, the lipid re-crystallises and leads to SLN [1].

Practically, SLN can be derived from the emulsions for parenteral nutrition just by replacing the liquid lipid (oil) of the emulsion droplets by a solid lipid. In contrast to emulsions for parenteral nutrition which are normally stabilised only by lecithin, the SLN are stabilised also by other surfactants or polymers which can act as a suspending agent in order to avoid particle aggregation.

This is a technique well established on the large scale for parenteral emulsions since the fifties and it is already available in the pharmaceutical industry. The production lines for parenteral emulsions are in most cases equipped with temperature control units because an increased temperature facilitates emulsion production, this means that existing production lines can be used for producing SLN by the hot homogenisation technique [1]. This technique allows the production of colloidal suspensions of SLN without solvents, which are generally used for polymeric nanoparticles, and this is a further advantage of this method from a toxicological point of view.

An important problem of SLN prepared through hot homogenisation is drug expulsion from nanoparticles, that can happen during lipid re-crystallisation on cooling of the hot nanoemul- 
sion. Consequently, in order to improve drug loading within nanoparticles and to prevent drug leakage during storage, a new generation of lipid nanoparticles has been prepared $[5,6]$. NLC (nanostructured lipid carriers) are characterised by a solid lipid core consisting of a mixture of solid and liquid lipids: the resulting matrix of the lipid particles shows a melting point depression compared to the original solid lipid, but the matrix is still solid at body temperature. Depending on the method of production and on the lipid blend composition, different types of NLC are obtained: imperfect, amorphous and multiple type. In the imperfect type, lipid crystallisation is altered by small amounts of oils. In the amorphous type, the lipid matrix is solid but not crystalline (amorphous state): this can be achieved by mixing special lipids, e.g. hydroxyoctacosanyl hydroxystearate with isopropyl myristate. In the multiple type the solid lipid matrix contains tiny oil compartments: they are obtained by mixing a solid lipid with a higher amount of oil. The basic idea is that by giving a certain nanostructure to the lipid matrix, the payload for active compounds is increased and expulsion of the compound during storage is avoided $[5,6]$.

SLN prepared through hot homogenisation are not suitable for the encapsulation of hydrophilic drugs, since they would partition preferentially to the external aqueous phase of the hot nanoemulsion: to overcome this limitation lipid drug conjugate (LDC) nanoparticles were developed. In a typical process, an insoluble drug-lipid conjugate bulk is first prepared either by salt formation (e.g. with a fatty acid) or by covalent linking (e.g. esters or ethers). The obtained LDC is then processed as the lipid for nanoparticles preparation $[7,8]$.

However, besides all its advantages and its versatility, HPH involves some critical process parameters like high temperatures, high pressures (cavitation forces), that may cause significant thermodynamic and mechanical stress for the resulting product: in particular this method is not suitable for thermo-sensitive drugs. Moreover, melted lipids are not good solvents for many drugs and this can cause a low drug loading in the SLN. For these reasons suitable alternative and easy handling production methods for lipid nanoparticles preparation have been widely investigated in last years [9].

\subsubsection{High shear homogenisation and ultrasound homogenisation}

High shear homogenisation and ultrasound homogenisation [10,11] are dispersing techniques which were initially used for the production of solid lipid nanodispersions. Both methods are widespread and easy to handle. However, dispersion quality is often compromised by the presence of microparticles. Furthermore metal contamination has to be considered if ultrasounds are used [2]. In the case of high shear homogenisation, SLN can be obtained owing to the use of proper emulsifying agent, which allow the formation of the hot nanoemulsion under simple high shear mixing [10].

\subsection{Melt dispersion technique}

In the melt dispersion technique, SLM can be obtained either from $\mathrm{O} / \mathrm{W}$ or multiple W/O/W emulsions, according respectively to the lipophilic or hydrophilic character of the drug. 
In the former case, lipophilic drug is dissolved into the melted lipids, which are emulsified with a hot surfactant solution through a high shear mixer: the obtained O/W emulsion is then cooled to room temperature to obtain solidification of lipid microparticles [12].

In the latter case, a heated hydrophilic drug solution is emulsified with a melted lipid in order to form a primary $\mathrm{W} / \mathrm{O}$ emulsion, which is then put in contact with an external aqueous phase at the same temperature; the resulting $\mathrm{W} / \mathrm{O} / \mathrm{W}$ multiple emulsion is then cooled to room temperature to form microparticles [13].

\subsection{PIT method}

The PIT (phase inversion temperature) method is commonly used for the preparation of nanoemulsions. The PIT concept uses the specific ability of some polyethoxylated surfactants to modify their affinities for water and oil as a function of the temperature. In the PIT nanoemulsion preparation method, the use of such surfactant type leads to an emulsion inversion from $\mathrm{O} / \mathrm{W}$ macroemulsion to a W/O emulsion when temperature is increased above the PIT, and to the formation of a $\mathrm{O} / \mathrm{W}$ nanoemulsion when the temperature is next lowered below the PIT [14].

The PIT method has been used also for the preparation of LNC (lipid nanocapsules), nanoparticles organised in an internal liquid or semiliquid oil core and an external lipid layer solid at room temperature [15].

Recently it has been adapted for the preparation of SLN. In this case two main components are used: an oil phase, constituted by solid lipids and non-ionic surfactants and an aqueous phase containing $\mathrm{NaCl}$. The aqueous phase and the oil phase are separately heated at $\sim 90^{\circ} \mathrm{C}$ (above the PIT); then the aqueous phase is added dropwise, at constant temperature and under agitation, to the oil phase, in order to obtain a W/O emulsion. The mixture is then cooled to room temperature under slow and continuous stirring. At the PIT, the turbid mixture becomes clear, then below the PIT an O/W nanoemulsion is formed, which turns in SLN below the lipid melting point [16].

\section{Microemulsion templates}

Another precursor which can be used for SLN preparation is the microemulsion.

Microemulsions are clear, thermodynamically stable, isotropic liquid mixtures of oil, water and surfactant, frequently in combination with a cosurfactant. The aqueous phase may contain salt(s) and/or other ingredients, and the "oil" may actually be a complex mixture of different hydrocarbons and olefins.

The concept of microemulsion was first introduced by Hoar and Schulman in 1943 [17]; they prepared the first microemulsion by dispersing oil in an aqueous surfactant solution and adding an alcohol as a cosurfactant, leading to a transparent, stable formulation.

The existence of this theoretical structure was later confirmed by the use of various technologies, and today we can adopt the definition given by Attwood [18]: "a microemulsion is a 
system of water, oil, and amphiphilic compounds (surfactant and cosurfactant) which is a transparent, single optically isotropic, and thermodynamically stable liquid".

The main difference between emulsions and microemulsions lies in the size - and shape of the particles dispersed in the continuous phase: these are at least an order of magnitude smaller in the case of microemulsions $(10-200 \mathrm{~nm})$ than those of conventional emulsions $(1-$ $20 \mu \mathrm{m})$. Also, whereas emulsions consist of roughly spherical droplets of one phase dispersed into the other, microemulsions are dynamic systems, constantly evolving between various structures ranging from droplet-like swollen micelles to bicontinuous structures.

Microemulsions are formed when and only when the interfacial tension at the oil/water interface is brought to a very low level and when the interfacial layer is kept highly flexible and fluid.

These two conditions are usually met by a careful and precise choice of the components and of their respective proportions, and by the use of a "cosurfactant" which brings flexibility to the oil/water interface [17].

This situation leads to a thermodynamically optimised structure, which is stable - as opposed to conventional emulsions - and does not require high input of energy (i.e. through agitation) to be formed. In contrast to ordinary emulsions, microemulsions form upon simple mixing of the components and do not require the high shear conditions generally used in the formation of ordinary emulsions.

Because the size of the particles is much smaller than the wavelength of visible light, microemulsions are transparent and their structure cannot be observed through an optical microscope.

The three basic types of microemulsions are direct $(\mathrm{O} / \mathrm{W})$, reversed $(\mathrm{W} / \mathrm{O})$ and multiple (W/O/W and $\mathrm{O} / \mathrm{W} / \mathrm{O})$.

Hot microemulsion can be used as template for SLN production: in this case the oil phase is made up of the solid lipid, liquefied above its melting point; SLN can be obtained through dilution of the hot microemulsion in cold water (microemulsion dilution technique) or by simple cooling of the hot microemulsion itself (microemulsion cooling technique).

Because of their unique solubilisation properties, microemulsions have attracted increasing attention as potential drug delivery systems for poorly water soluble active pharmaceutical ingredients (API) [19]; also the good solubilisation properties of hot microemulsion precursor allows an advantageous drug loading within SLN for many drugs, especially for poorly water soluble drugs.

\subsection{Microemulsion dilution technique}

Gasco [20] was the first researcher to use a microemulsion template for the preparation of SLN. Lipids are heated above their melting point and an aqueous phase containing surfactants and cosurfactants is added at the same temperature in order to form a clear $\mathrm{O} / \mathrm{W}$ microemulsion under stirring; lipophilic drug can be dissolved in the hot microemulsion. Multiple W/O/W 
microemulsion can be prepared, too, in order to encapsulate hydrophilic drugs within SLN $[21,22]$. SLN with reduced mean particle size and narrow size distribution can be obtained after dilution in $\operatorname{cool}\left(2-10^{\circ} \mathrm{C}\right)$ water of the hot microemulsion.

The lipids employed can be triglycerides, fatty acids, fatty alcohols. Surfactants can be chosen among bile salts, phospholipids, polysorbates and cosurfactants among short chain alcohols and glycols (butanol, hexanol, hexanediol, propylene glycol), short chain fatty acids (butyric acid, hexanoic acid), phosphoric acid alkyl esters and benzyl alcohol [20].

Dilution of the microemulsion can be performed with a volume of water 10 to 200 compared to microemulsion volume.

\subsection{Microemulsion cooling technique}

Recently, Mumper and Jay [23,24] patented a microemulsion based method to produce SLN. The technique is simple, reproducible, and easy to scale-up. In particular for the production of SLN the authors start from an O/W microemulsions: an emulsifying wax is melted (37-55 ${ }^{\circ} \mathrm{C}$ ) and water is then added at the same temperature under minimal stirring to form an homogeneous milky slurry. Upon the addition of defined amounts of a suitable pharmaceutically-acceptable polymeric surfactant in water, a clear and stable liquid matrix $\mathrm{O} / \mathrm{W}$ microemulsion is formed. SLN are precipitated from this $\mathrm{O} / \mathrm{W}$ microemulsion by cooling of the undiluted $\mathrm{O} / \mathrm{W}$ microemulsion to room temperature or to $4{ }^{\circ} \mathrm{C}$.

The matrix material may be selected from a variety of excipients including for examples waxes, such as emulsifying wax (Polysorbate 60, PEG-150 Stearate and Steareth-20), the polymeric surfactants can be chosen among the Brij ${ }^{\circledR}$-type, polyethylene glycol derivatives of fatty acids such as PEG-400 monostearate, and phospholipids such as phosphatidylcholine (lecithin).

An advantage of this invention is that the described nanoparticle system can be formulated at mild operating temperatures, rapidly, reproducibly and cost-effectively from the microemulsion precursor in an one-step process and contained in a manufacturing vessel, vial or container.

Moreover all ingredients are potentially biocompatible, well-defined and uniform solid nanoparticles (50 to $300 \mathrm{~nm}$ ) may be reproducibly made, no organic solvents were used during the preparation, very high entrapment efficiencies are achievable [25], especially for waterinsoluble drugs, and cell-specific ligands can easily be incorporated on the surface of the nanoparticles [26].

\section{Coacervation method}

Recently, a new method was developed to prepare-in a controlled way-SLN by coacervation. This method allows the incorporation of drugs, without using very complex equipment or dangerous solvents, and is therefore inexpensive for laboratory and industrial application. It is based on the interaction between a micellar solution of a fatty acid alkaline salt (soap) and 
an acid solution (coacervating solution) in the presence of different amphiphilic polymeric stabilizing agents: fatty acid nanoparticles precipitate as proton exchange occurs between the coacervating solution and the soap solution $[27,28]$.

In this method the precursor for SLN preparation is a soap micellar solution, obtained at a temperature above its Krafft point (that is the solubilisation temperature of the soap in water): drug can be dissolved directly in the micellar solution, or pre-dissolved in a small amount of ethanol, in order to enhance micellisation. As for microemulsion templates, the good solubilising properties of micellar solutions allow an advantageous drug loading within SLN for many drugs, especially for poorly water soluble drugs [29, 30].

The salt of fatty acid is chosen from the group consisting from sodium stearate, sodium palmitate, sodium myristate, sodium arachidate and sodium behenate in a concentration preferably between 1 and $5 \% \mathrm{w} / \mathrm{w}$. The stabilizing agent is selected from the group of surface active non ionic polymers: polyvynilacetate/polyvynilalcohol and polyoxyethylene/polyoxypropylene copolymers, dextrans, hydroxypropylmethylcellulose. Normally the acidification takes place at a temperature between 40 and $50{ }^{\circ} \mathrm{C}$, above the Krafft point of the fatty acid sodium salt; sodium arachidate and behenate need higher temperatures. Then the obtained suspension is rapidly cooled to $15^{\circ} \mathrm{C}[27,28]$.

A very important feature of this method is the possibility to control the size of SLN changing the reaction conditions. In order to obtain a homogeneous and stable nanoparticle suspension, a key role is played by the right coupling between the fatty acid alkaline salt and the proper coacervating solution. Particle size is highly influenced by the lipid concentration: increasing the micellar solution concentration the SLN size increases. Also the type and the grade of the polymer used as stabiliser influence the SLN mean particle size [28].

\section{Solvent based methods}

Solvent based methods have been proposed in order to encapsulate molecules with stability and bioavailability problems, despite toxicological issues of the solvent are a limiting aspect. One of the main advantages of solvent based methods is the mild operating temperature, which can be useful for the encapsulation of thermosensitive drugs. According to the different precursor/method used, solvent based methods can be divided in:

- solvent injection;

- solvent evaporation from emulsions;

- solvent diffusion from emulsions.

\subsection{Solvent injection method}

In solvent injection (or solvent displacement) method the lipid and the drug are dissolved in a water-miscible organic solvent (ethanol, acetone, isopropanol) and this solution is injected through a syringe needle in water under stirring: lipid precipitates as nanoparticles while 
contacting water, encapsulating the drug. Particle size can be influenced by lipid type, surfactant and solvent used, and from the viscosity of the outer phase [31,32].

\subsection{Solvent evaporation - Diffusion from emulsions}

SLN can also be prepared starting from emulsion precursor, whose organic phase is constituted by a solvent, which can be either volatile or partially water miscible.

$\mathrm{O} / \mathrm{W}$ or W/O/W emulsions can be prepared: $\mathrm{O} / \mathrm{W}$ emulsions are used for lipophilic drugs, that are dissolved in the inner organic phase of the system [33,34], together with the lipid. W/O/W emulsions are suitable for hydrophilic drugs, that are dissolved in the inner aqueous phase, while the lipid is dissolved in the intermediate organic phase of the multiple system $[35,36]$.

Nanoparticles are formed when the solvent is removed either by evaporation (solvent evaporation technique for volatile solvents) $[33,35]$ or by water dilution (solvent diffusion technique for partially water miscible solvents) [34, 36]: owing to solvent removal lipid precipitates as nanoparticles encapsulating the drug.

Solvent evaporation technique is quite outdated and shows many drawbacks, due to the toxicity of chlorinated solvents used; solvent diffusion is more innovative and most of the solvent employed show a better safety profile compared to volatile solvents.

\section{Supercritical fluid based methods}

Supercritical fluid (SCF) technology has gained increasing interest in the last years for nanoparticle production. SCF is obtained above its critical pressure and temperature: above this fluid's critical point, the solubility of a substance in the fluid can be modulated by a relatively small change in pressure. Due to its low critical point at $31^{\circ} \mathrm{C}$ and $74 \mathrm{bar}$, and its low cost and non toxicity, carbon dioxide $\left(\mathrm{CO}_{2}\right)$ is the most widely used SCF [37].

The four main SCF processes used to produce nano-or microparticles are:

1. Rapid Expansion of Supercritical Solutions (RESS);

2. Gas Anti-Solvent (GAS) process;

3. Particles from Gas-saturated Solutions/Suspensions (PGSS);

4. Supercritical Fluid Extraction of Emulsions (SFEE).

\subsection{RESS}

RESS, which is also called supercritical fluid nucleation (SFN), is based on a simple principle: the matrix is dissolved in SCF, which is then expanded through a nozzle, in order to form the particles [38]. This major limitation of RESS lies in the too low solubility of compounds in SCF, that precludes production at acceptable costs. In fact its applications to lipid particles is very limited. 
A modified RESS process has been used for lipid coating of bovine serum albumin (BSA) microcrystals [39]. The lipid coated microparticles are prepared as follows: coating material and BSA crystals are placed in an autoclave, equipped with a rotating impeller, heated and pressurised with $\mathrm{CO}_{2}$ (temperature typically ranging between 35 and $45^{\circ} \mathrm{C}$ and pressure about 200 bar). The system is allowed to equilibrate at these conditions, so as to solubilise the coating material. Then, cooling the autoclave induced a pressure decrease and a phase change from SCF to liquid state, therefore insolubilising the coating material that precipitated upon the insoluble BSA crystals dispersed in the medium. Afterwards, the autoclave is vented to ambient conditions and the coated particles are collected from the bottom of the autoclave.
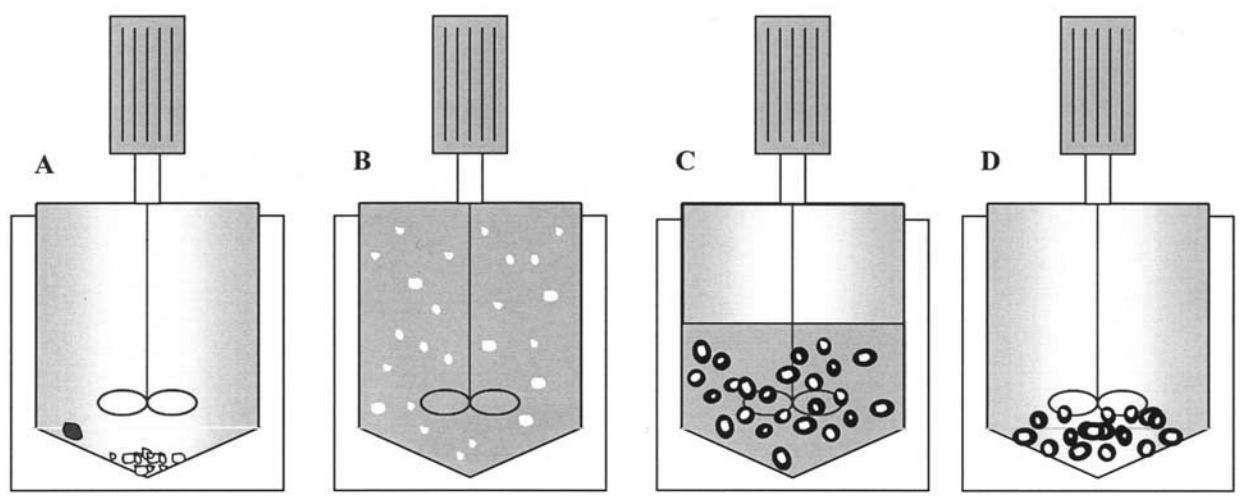

Figure 1. Schematic representation of the coating process. (A) Filling step: BSA crystals represented in white, coating material in black. (B) Solubilisation of the coating material in the SCF $\mathrm{CO}_{2}$. Insoluble BSA crystals are dispersed in the medium. (C) Decompression phase: insolubilisation of the coating material. (D) Coated particles are harvested after autoclave has been vented.

\subsection{GAS}

GAS process has been developed in order to achieve nanosizing of the hydrophobic materials that can not be processed by RESS technique owing to their poor solubility in SCF. The origin of GAS process is based on the fact that when a solution is expanded sufficiently by a gas, the liquid phase is no longer a good solvent for the solute and nucleation occurs [38]. Up to now GAS technique has very limited applications for lipid particles.

\subsection{PGSS}

PGSS involves melting of the material to be processed, which then dissolves the SCF under pressure. The saturated solution is then expanded across a nozzle where the SCF, which is more volatile, escapes, leaving dry fine particles. As the solubilities of compressed gases in liquids and solids are usually high, and much higher than the solubilities of such liquids and solids in the compressed gas phase, the process consists in solubilizing $\mathrm{CO}_{2}$ in melted or liquidsuspended substance(s), leading to a so-called gas-saturated solution/suspension that is 
further expanded through a nozzle with the formation of solid particles or droplets. The advantage of this process is that the substances need not be soluble in $\mathrm{CO}_{2}$ [38].

In literature some examples of PGSS applied to lipid nano-and microparticles can be recovered. The most important is the so called Gas Assisted Melting Atomisation (GAMA) [40,41,42].

Lipids are placed in a thermostated mixing chamber $(\mathrm{CM})$, where they are melted and kept in contact with supercritical $\mathrm{CO}_{2}$ at selected temperature and pressure conditions (Figure 2). Then, the lipid saturated fluid is forced through the nozzle by opening the valve at the bottom of the $\mathrm{CM}$, in order to produce microparticles. $\mathrm{A} \mathrm{CO}_{2}$ reservoir is allowed to keep constant the pressure in the $\mathrm{CM}$, and the flow rate through the nozzle as well. Particles are gathered by a collection system and dispersed in water by vortexing and sonicating, in order to obtain suspensions. Polyethylenglycol (PEG) can be added to the formulation in order to increase the rate of dispersion in water.

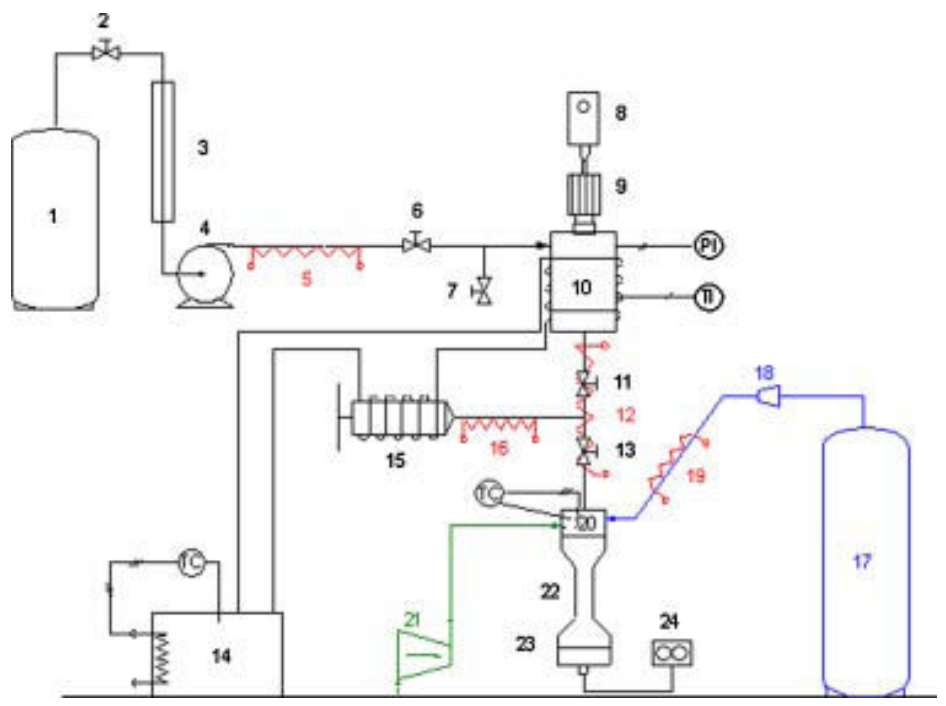

Figure 2. GAMA apparatus for micro and nanoparticles production: supercritical $\mathrm{CO}_{2}$ supplier (1), on-off valves $(2,6,7,11,13)$, heater exchanger (3), pump (4), electrical resistances $(5,12,16,19)$, pressure indicator (PI), temperature indicator ( $\mathrm{TI})$, temperature controller (TC), mixing device (8,9), melting chamber (10), heating system (14), spraying pump (15), air supplier (17), pressure reducer (18), $100 \mathrm{~mm}$ diameter nozzle (20), compressor for tangential air flux (21), precipitation vessel (22), filter (23), flowmeter (24).

\subsection{SFEE}

SFEE is based on a simple principle, whereby the lipid nanosuspensions are produced by supercritical fluid extraction of the organic solvent from $\mathrm{O} / \mathrm{W}$ emulsions. $\mathrm{O} / \mathrm{W}$ emulsion is prepared by dissolving lipid and drug in a volatile solvent (i.e. chloroform), dispersing this solution into an aqueous phase of a surfactant and passing the mixture through a high pressure 
homogeniser in order to form fine emulsions with a mean droplet size ranging between 30 $100 \mathrm{~nm}$.

SLN suspensions are obtained using a continuous extraction method. The O/W emulsions are introduced into an extraction column from the top; simultaneously, supercritical $\mathrm{CO}_{2}$ (at constant pressure of 80 bar and temperature $35^{\circ} \mathrm{C}$ ) is introduced counter-currently from the bottom $[43,44]$ (Figure 3).

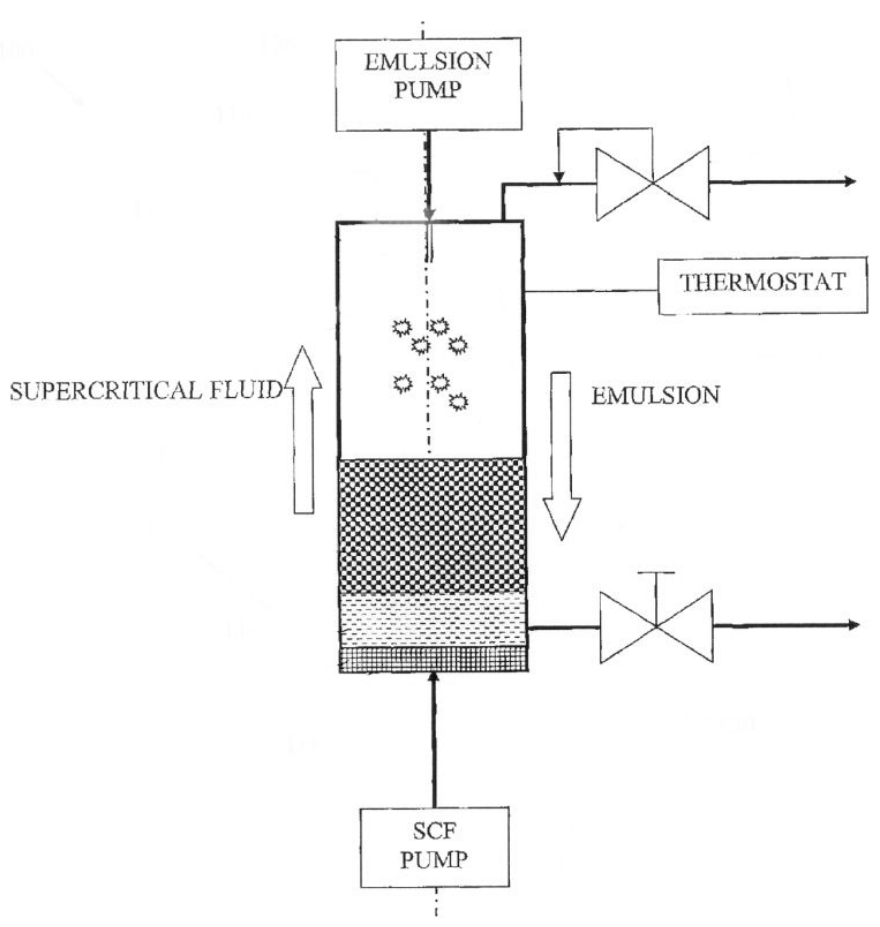

Figure 3. Extraction column for emulsion with SCF in counter-current

The operating pressure and temperature conditions have to be selected to minimise losses of product due to lipid and drug dissolution into the $\mathrm{CO}_{2}$ phase at maximum extraction efficiency. The residence time required for producing pure aqueous suspensions of SLN is approximately two minutes, with the product continuously removed from the bottom of the extraction column.

When the $\mathrm{O} / \mathrm{W}$ emulsion containing the lipid and the drug is introduced into the supercritical $\mathrm{CO}_{2}$ phase, parallel processes of solvent extraction into the supercritical $\mathrm{CO}_{2}$ phase, and the inverse flux of $\mathrm{CO}_{2}$ into the emulsion droplets occurs, leading to expansion of the organic phase of the emulsion. This in turn leads to precipitation of lipid-drug material dissolved in the organic phase as composite particles [44]. 
One of the advantages of this technique is that the solvent extraction efficiency using supercritical $\mathrm{CO}_{2}$ is much higher than for the conventional methods, such as solvent evaporation/ diffusion from emulsions. It therefore provides for a fast and complete removal of the solvent and more uniform particle size distribution. Supercritical $\mathrm{CO}_{2}$ also tends to extract other lowmolecular weight impurities, purifying the lipids. The size of SLN obtained in the SFEE process is directly related to the emulsion droplet size and it is therefore dependent upon the method of formulation; a mean particle diameter between 20-90 $\mathrm{nm}$ can be obtained [44].

\section{Membrane contactor technique}

SLN can be produced by using a membrane contactor [45]: a proper module has been realised (Figure 4$)$, including a Kerasep ceramic membrane $(0.1,0.2,0.45 \mu \mathrm{m}$ pore size), which separates the water phase, allowed to circulate tangentially to the membrane surface, and the lipid phase; the lipid phase is heated in a pressurised vessel above its melting point, conveyed through a tube to the module (Figure 5) and pressed through the membrane pores, allowing the formation of small droplets, which are detached from the membrane pores by tangential water flow. SLN are formed after cooling of the obtained water dispersion [46].

SLN particle size depends on many process parameters: larger sizes are obtained with higher lipid phase content, reduced lipid phase pressure and aqueous cross-flow velocity. If the temperature of the aqueous phase is below the melting point of the lipid, smaller SLN are obtained: this is due to the fact that the lipid phase solidifies suddenly in the aqueous phase. Instead the SLN size decreases when the lipid temperature increases. Particle size is also highly influenced by type and concentration of surfactants added to the formulation [47].

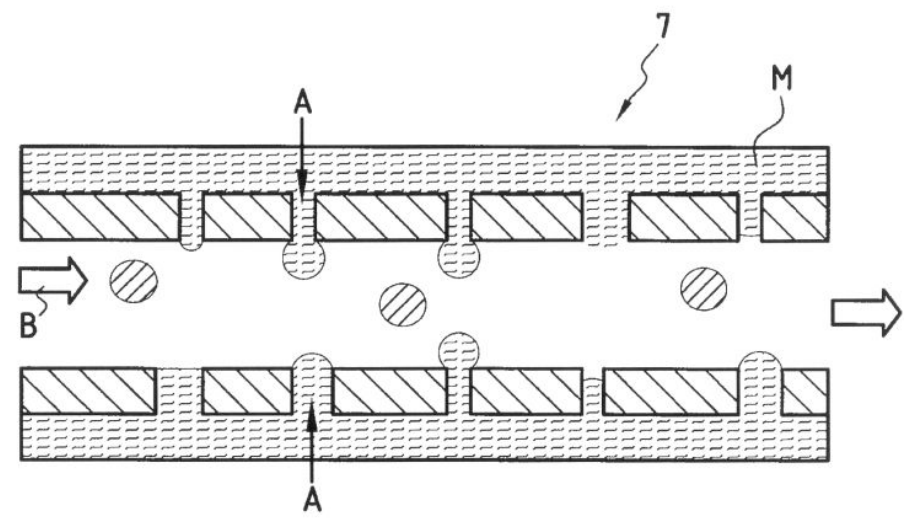

Figure 4. Module for membrane contactor. A (lipid phase), B (water phase), M (porous membrane), 7 (tangential flow filtration unit). 


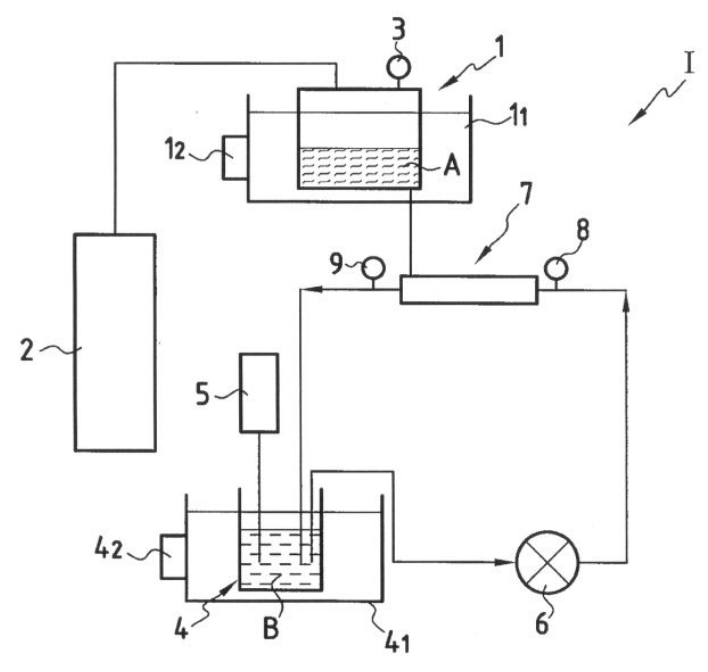

Figure 5. Scheme of the apparatus for producing SLN with a membrane contactor. A (lipid phase), B (water phase), 1 (pressurised vessel containing the lipid phase), $1_{1}$ (thermostated bath), $1_{2}$ (thermostat), 2 (nitrogen bottle), 3 (manometer), 4 (vessel containing the water phase), $4_{1}$ (thermostated bath), $4_{2}$ (thermostat), 5 (stirrer), 6 (pump), 7 (tangential flow filtration unit), 8-9 (manometer).

\section{Cryogenic micronisation}

In the cryogenic micronisation process, lipid matrices are obtained either by melt dispersion (the drug is mixed in a molten lipid) or solvent stripping (the drug and lipid are co-dissolved into a solvent mixture under stirring, e.g. benzyl alcohol, ethanol). In the cryogenic micronisation step, cooling is performed by insufflating liquid nitrogen nearly at- $80^{\circ} \mathrm{C}$ before the drug loaded lipid matrix being micronised by grinding.

Finally, the obtained powders are sieved in an automatic sieving apparatus. Regarding to the sieving step, this operation is depending on particle size requirements and on the type of mill used, the particle size of the product obtained by micronisation can already be suitable for some applications and therefore sieving is not necessary.

This technique can be used for the production of SLM of 1 to $500 \mu \mathrm{m}$ in diameter according to the chosen sieves [48,49].

\section{Spray-drying}

Spray-drying is an one-step process which converts a liquid feed to a dried particulate form. The feed generally is a solution, but it can also be a coarse or fine suspension or a colloidal 
dispersion (e.g., emulsions, liposomes, etc.); this feed is first atomised through various techniques (centrifugal, pneumatic, ultrasonic and electrostatic atomisation) to a spray form, that is put immediately into thermal contact with a hot gas, resulting in the rapid evaporation of the solvent to form dried solid particles [50]. The dried particles are then separated from the gas by means of a cyclone, an electrostatic precipitator or a bag filter (Figure 6).

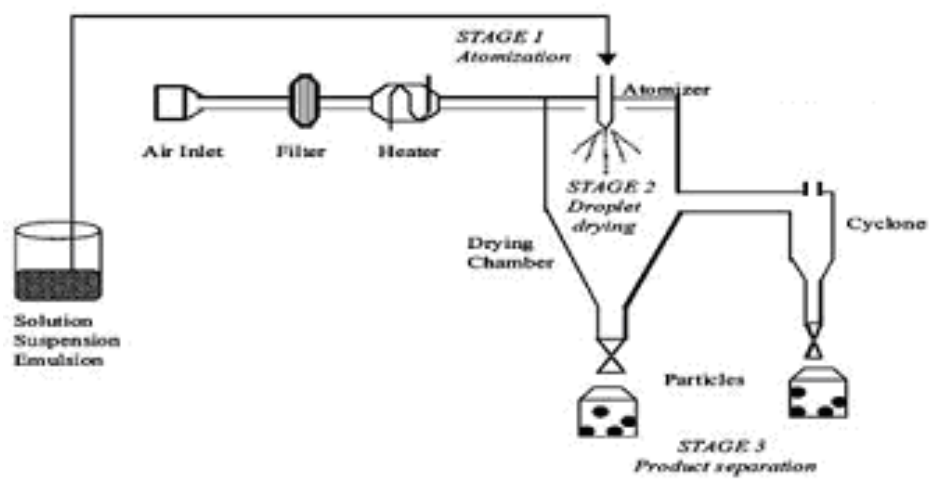

Figure 6. Spray-drying apparatus

The design may be "open cycle", when the drying gas (usually air) is not recirculated and is vented into the atmosphere. If an organic solvent is employed, a "closed cycle" layout is more suitable than an open one, since the risk of inflammability and explosion is higher in the latter when organic feeds are heated in the presence of oxygen [51].

The main advantage of the spray-drying technique is the ability to manipulate and control a variety of parameters such as solvent composition, solute concentration, solution and gas flow rate, temperature and relative humidity, droplet size, etc. So the optimisation of particle characteristics can be performed in terms of size, size distribution, shape, morphology and density, in addition to macroscopic powder properties like bulk density, flowability and dispersibility [51].

However, the spray-drying process may induce degradation of some macromolecular drugs as a result of a number of factors such as thermal stress during droplet drying, high shear stress in the nozzle and peptide/protein adsorption at the greatly expanded liquid/air interface of the spray solution.

Sebti et al. have developed a spray-drying technique to produce SLM. These SLM are composed of biocompatible phospholipids and cholesterol, and can be used as a carrier or filler to deliver drugs directly to the lungs via a dry powder inhaler [52,53]. SLM are obtained by starting from an ethanolic solution of lipids and drug, which undergo to spray-drying process. Compared to other SLM production methods, spray-drying produces particles which are characterised by smaller and more homogeneous particle size distribution. However, the produced particles are not always spherical and may have convoluted surfaces, asperities and cavities. The shape 
is influenced by the drying rate, the surface tension and the viscosity of the liquid which constitutes the liquid feed.

\section{Electrospray}

In a general process, a solution of the matrix, which constitutes the particles, is contained in a syringe, with a metal capillary connected to a high-voltage power supply, working as an electrode. A metal foil collector is placed opposite the capillary as a counter electrode (Figure 7). Depending on the properties of the liquid, the flow rate and the voltage applied can be modulated.

The cone-jet mode is the method used to prepare nanoparticles, in which liquid emerging at the nozzle forms hemispherical drops because of the surface tension. By increasing the electrical field, the hemispherical drops can be changed to a conical shape, which breaks up into highly charged droplets. By selecting suitable conditions, droplets can be produced with a close size distribution and nano-or micrometer size range. Particles can be formed by evaporating the solvent from the droplets produced travelling through the electrical field.

The electrospray method has been employed to prepare monodisperse lipid-based nano-and microparticles: lipid has been dissolved in aliphatic alcohols and this solution has been used for particles production. Particle shape and size depend on the solvent and excipients used and on the applied voltage $[54,55]$.

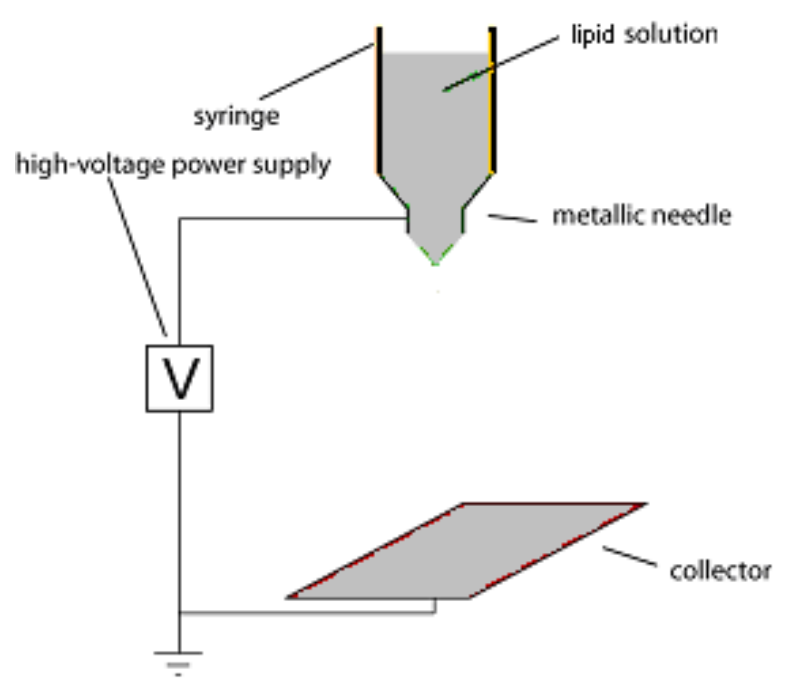

Figure 7. Scheme of electrospray apparatus 


\section{Spray congealing}

In the spray congealing technique, lipids are heated to a temperature above their melting point and the drug is dissolved or suspended into the melted lipid. The hot mixture is then atomised through a pneumatic nozzle into a vessel, where the atomised droplets can solidify in the form of microparticles [56]. In this technique some variations can be performed, especially in the atomisation device.

The Wide Pneumatic Nozzle (WPN) (Figure 8A) is an innovative external mixing atomiser: the molten fluid and the atomisation air get in contact outside the nozzle; the former is delivered to the orifice by the Venturi effect, while the latter is delivered in radial direction with respect to the molten fluid. The atomisation occurs where the air input converges with the molten fluid [57].

The Air Pressure Nozzle (APN) (Figure 8B) is an internal mixing device: the molten fluid and the atomisation air get in contact in the mixing chamber inside the nozzle. The swirling fluid impinges on the plate and the interaction between the fluid and the air creates extreme turbulence in the chamber, and then flows through an orifice, where the droplets are exposed to shear forces, before coming in contact with a circular deflector ring and leaving the nozzle as a finely atomised spray cone [57].
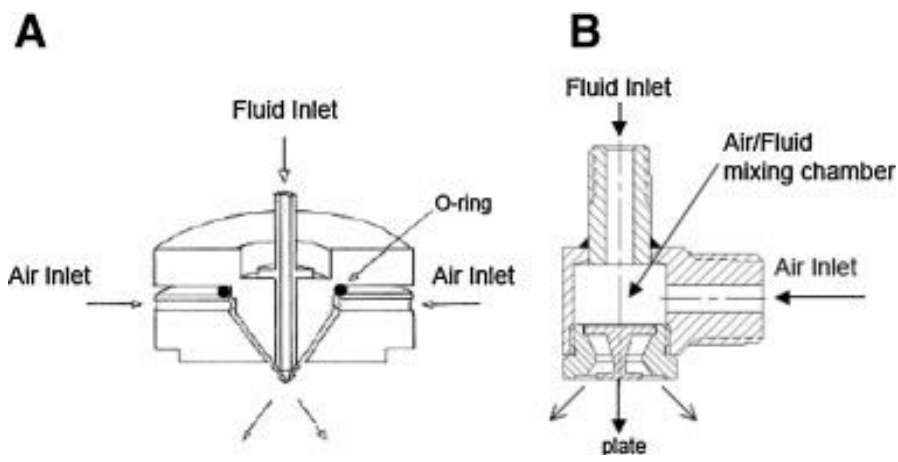

Figure 8. A) Diagram of the external-mixing WPN. B) Diagram of the internal mixing APN

Another particular type of atomiser is based on ultrasounds [58]. The ultrasound-atomiser basically consists of three parts (Figure 9):

1. the ultrasound piezoelectric generator;

2. an interchangeable booster allowing for the modification of the amplitude of the ultrasound wave;

3. a titanium vibrating surface (sonotrode) on which the atomisation of the liquid occurs.

The atomiser is also provided of an inductive coil to keep the sonotrode at suitable temperature. 
The melted lipid mixture, fed to the sonotrode by a thermostated reservoir through a funnel, is atomised by ultrasound energy into small droplets that fall freely and solidify by cooling at room temperature in a collector.

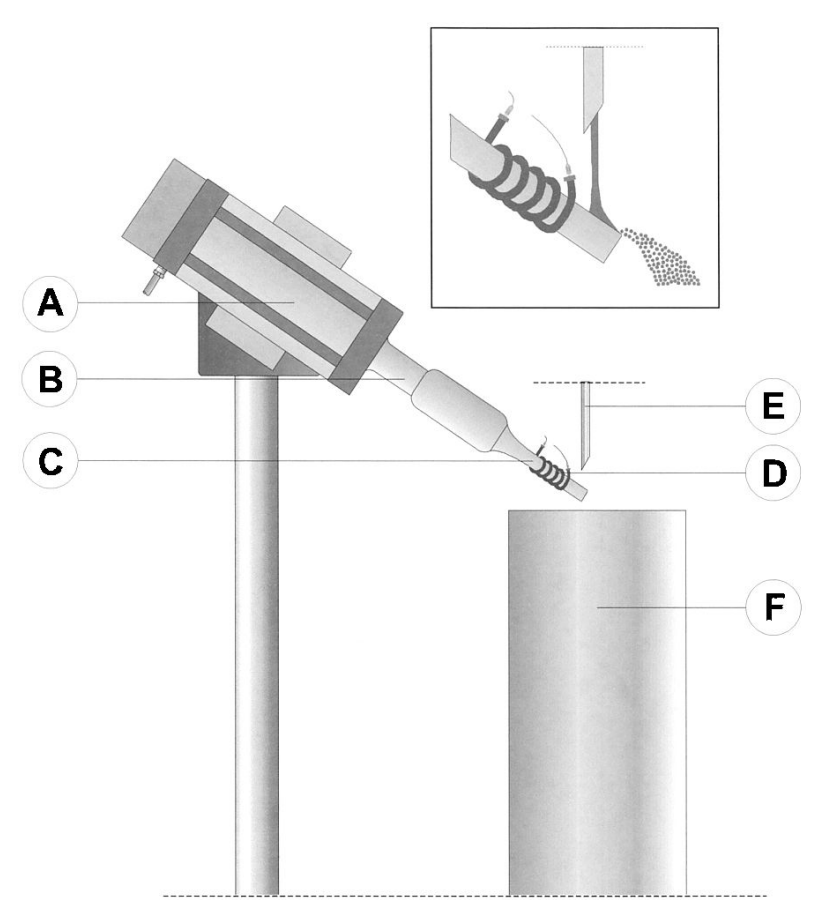

Figure 9. Scheme of the ultrasonic atomiser (not in scale): (A) ultrasound generator; (B) booster; (C) sonotrode; (D) inductive coil; (E) supply funnel; (F) cylindrical chamber (collector).

Another variant of the spray congealing method is to use a rotating disc [59]. With this technique, the melted mixture is dropped onto a high-speed rotating disc. The rotation induces the molten mixture to spread between the disc periphery and the cooled surface on which microparticles are collected.

Owing to this technique SLM with particle size ranging from 50 to $2000 \mu \mathrm{m}$ can be produced.

\section{Conclusion}

Different techniques have been developed for the production of solid lipid particles with the possibility to obtain different size and shape. The size can influence the pharmacological properties of the particles, but it is not the unique parameter considered to compare the various techniques. 
Toxicological issues are also very important: the materials used must be biocompatible and biodegradable, while the use of solvents can be a relevant drawback, since they can remain in traces in the final product.

From a technological point of view, the possibility to scale up the process is very important, but also the feasibility of the method is relevant: in fact the use of expensive and complex machine can hamper the production on lab scale.

Finally the drug entrapment is very important: nowadays more and more complex molecules are entrapped within solid lipid particles. These molecules have different physico-chemical properties (solubility, hydrophobicity, etc.) and stability issues (temperature, $\mathrm{pH}$, etc.). The chosen preparation technique should be the most suitable to enhance drug loading and encapsulation efficiency within the nanoparticles, without hampering the chemical stability of the molecule itself: the working temperatures and operating conditions used to prepare the particles can affect the physico-chemical stability of the drug.

In Table 2 some important parameters, like particle size, solvents used, instrumentation needed, working temperatures and operating conditions, of the various techniques are shown for comparative purposes.

\begin{tabular}{|c|c|c|c|c|c|}
\hline Technique & Particle size & Solvent used & $\begin{array}{l}\text { Instrumentation } \\
\text { needed }\end{array}$ & $\begin{array}{c}\text { Working } \\
\text { temperature }\end{array}$ & $\begin{array}{l}\text { Operating } \\
\text { conditions }\end{array}$ \\
\hline $\begin{array}{l}\text { High pressure } \\
\text { homogenisation }\end{array}$ & $50-1000 \mathrm{~nm}$ & & $\begin{array}{l}\text { High pressure } \\
\text { homogeniser }\end{array}$ & $\begin{array}{l}\text { 5- } 10^{\circ} \mathrm{C} \text { upon } \\
\text { lipid mp }\end{array}$ & $\begin{array}{l}\text { cavitation } \\
\text { forces }\end{array}$ \\
\hline $\begin{array}{l}\text { High shear } \\
\text { homogenisation }\end{array}$ & $50-1000 \mathrm{~nm}$ & & $\begin{array}{l}\text { High shear } \\
\text { homogeniser }\end{array}$ & $\begin{array}{c}\text { 5-10 } 10^{\circ} \mathrm{C} \text { pon } \\
\text { lipid } \mathrm{mp}\end{array}$ & \\
\hline $\begin{array}{l}\text { Ultrasound } \\
\text { homogenisation }\end{array}$ & $50-1000 \mathrm{~nm}$ & & $\begin{array}{l}\text { Ultrasound } \\
\text { apparatus }\end{array}$ & $\begin{array}{c}\text { 5-10 } \\
\text { lipid } \mathrm{mp}\end{array}$ & $\begin{array}{l}\text { Ultrasound } \\
\text { treatment }\end{array}$ \\
\hline Melt dispersion & $1-250 \mu \mathrm{m}$ & & $\begin{array}{l}\text { High shear } \\
\text { homogeniser }\end{array}$ & $\begin{array}{l}\text { 5-10 }{ }^{\circ} \mathrm{C} \text { upon } \\
\text { lipid } \mathrm{mp}\end{array}$ & \\
\hline PIT & $30-100 \mathrm{~nm}$ & & & $90^{\circ} \mathrm{C}$ & \\
\hline Microemulsion dilution & $50-800 \mathrm{~nm}$ & & & $\begin{array}{c}\text { 5-10 } \mathrm{C} \text { upon } \\
\text { lipid } \mathrm{mp}\end{array}$ & \\
\hline Microemulsion cooling & $50-300 \mathrm{~nm}$ & & & $37-55^{\circ} \mathrm{C}$ & \\
\hline Coacervation & $200-1000 \mathrm{~nm}$ & & & $\begin{array}{l}40-75^{\circ} \mathrm{C} \\
\text { according to the } \\
\text { lipid matrix }\end{array}$ & pH shifts \\
\hline Solvent injection & $100-500 \mathrm{~nm}$ & $\begin{array}{l}\text { Ethanol, } \\
\text { acetone, } \\
\text { isopropanol }\end{array}$ & & $25^{\circ} \mathrm{C}$ & \\
\hline
\end{tabular}




\begin{tabular}{|c|c|c|c|c|c|}
\hline Technique & Particle size & Solvent used & $\begin{array}{l}\text { Instrumentation } \\
\text { needed }\end{array}$ & $\begin{array}{c}\text { Working } \\
\text { temperature }\end{array}$ & $\begin{array}{l}\text { Operating } \\
\text { conditions }\end{array}$ \\
\hline $\begin{array}{l}\text { Solvent evaporation from } \\
\text { emulsions }\end{array}$ & $30-500 \mathrm{~nm}$ & $\begin{array}{l}\text { Chlorinated } \\
\text { solvents }\end{array}$ & $\begin{array}{l}\text { High shear/pressure } \\
\text { homogeniser }\end{array}$ & $25^{\circ} \mathrm{C}$ & \\
\hline $\begin{array}{l}\text { Solvent diffusion from } \\
\text { emulsions }\end{array}$ & $100-2000 \mathrm{~nm}$ & $\begin{array}{l}\text { Partially water } \\
\text { miscible } \\
\text { solvents }\end{array}$ & $\begin{array}{c}\text { High shear/pressure } \\
\text { homogeniser }\end{array}$ & $40-50^{\circ} \mathrm{C}$ & \\
\hline PGSS & $0.2-20 \mu \mathrm{m}$ & & GAMA apparatus & $\begin{array}{l}\text { 5-10 } \mathrm{C} \text { upon } \\
\text { lipid mp }\end{array}$ & $\begin{array}{c}\text { Pressure }>74 \\
\text { bar }\end{array}$ \\
\hline SFEE & $20-90 \mathrm{~nm}$ & $\begin{array}{l}\text { Chlorinated } \\
\text { solvents }\end{array}$ & $\begin{array}{l}\text { High pressure } \\
\text { homogeniser } \\
\text { SFEE apparatus }\end{array}$ & $>31^{\circ} \mathrm{C}$ & $\begin{array}{c}\text { Pressure }>74 \\
\text { bar }\end{array}$ \\
\hline Cryogenic micronisation & $1-500 \mu \mathrm{m}$ & & & $-80^{\circ} \mathrm{C}$ & \\
\hline $\begin{array}{l}\text { Membrane contactor } \\
\text { method }\end{array}$ & $100-200 \mathrm{~nm}$ & & Membrane contactor & $\begin{array}{l}\text { 5-10 } 10^{\circ} \text { upon } \\
\text { lipid mp }\end{array}$ & \\
\hline Spray-drying & $0.3-10 \mu \mathrm{m}$ & Ethanol & Spray-drier & $70^{\circ} \mathrm{C}$ & \\
\hline Electrospray & Nearly $1 \mu \mathrm{m}$ & $\begin{array}{l}\text { Aliphatic } \\
\text { alcohols }\end{array}$ & $\begin{array}{l}\text { Electropray } \\
\text { apparatus }\end{array}$ & $25^{\circ} \mathrm{C}$ & High voltage \\
\hline Spray-congealing & $50-2000 \mu \mathrm{m}$ & & $\begin{array}{l}\text { Spray-congealing } \\
\text { apparatus }\end{array}$ & $\begin{array}{l}5-10^{\circ} \mathrm{C} \text { upon } \\
\text { lipid } \mathrm{mp}\end{array}$ & \\
\hline
\end{tabular}

Table 2. Main parameters for the various preparation techniques of solid lipid nano-and microparticles

As it can be noticed, each technique leads to the formulation of particles with different size and shows some limitations and drawbacks: the choice of a preparation technique should be done basing on the desired particle size, on the technology available, on the toxicological issues and on the characteristics of the drug encapsulated within the particles.

\section{Author details}

Luigi Battaglia ${ }^{1 *}$, Marina Gallarate ${ }^{1}$, Pier Paolo Panciani ${ }^{2}$, Elena Ugazio ${ }^{1}$, Simona Sapino ${ }^{1}$, Elena Peira ${ }^{1}$ and Daniela Chirio ${ }^{1}$

*Address all correspondence to: luigi.battaglia@unito.it

1 University of Turin, Department of Drug Science and Technology, Turin, Italy

2 Department of Neurosciences, University of Brescia, Brescia, Italy 


\section{References}

[1] Müller R.H., Mader K., Gohla S. Solid lipid nanoparticles (SLN) for controlled drug delivery: a review of the state of the art. Eur J Pharm Biopharm 2000; 50: 161-177

[2] Mehnert W., Mader K. Solid lipid nanoparticles: production, characterization, and applications. Adv Drug Deliver Rev 2001; 47: 165-196

[3] Jaspart S., Piel G., Delattre L., Evrard B. Solid lipid microparticles: formulation, preparation, characterisation, drug release and applications. Expert Opin Drug Del 2005; 2: $75-87$

[4] Müller R.H., Lucks J.S. Arzneistoffträger aus festen Lipidteilchen-Feste Lipid Nanosphären (SLN). EP0605497 (1996)

[5] Müller R.H., Petersen R.D., Hommoss A., Pardeike J. Nanostructured lipid carriers (NLC) in cosmetic dermal products. Adv Drug Deliver Rev 2007; 59: 522-530

[6] Müller R.H., Souto E.B., Radtke M. Lipid particles on the basis of mixtures of liquid and solid lipids and methods for producing same. EP00/04111 (2000)

[7] Olbrich C., Müller R.H., Kayser O. Lipid drug conjugate nanoparticles as novel carrier system for the hydrophilic antitrypanosomal drug diminazene aceturate. J Drug Target 2002; 10: 387-396

[8] Müller, R.H. Medicament vehicle for the controlled administration of an active agent, produced from lipid matrix-medicament conjugates. WO00/67800 (2000)

[9] Corrias F., Lai F. New methods for lipid nanoparticles preparation. Recent Pat Drug Deliv Formul 2011; 5: 201-213

[10] Carlotti M.E., Sapino S., Trotta M., Battaglia L., Vione D., Pelizzetti E. Photostability and stability over time of retinyl palmitate in an o/w emulsion and in SLN introduced in the emulsion. J Disper Sci Technol 2005; 26: 125-138

[11] DongZhi Hou, ChangSheng Xie, KaiJin Huang, ChangHong Zhu. The production and characteristics of solid lipid nanoparticles (SLNs). Biomaterials 2003; 24: 17811785 .

[12] Bodmeier R., Wang J., Bhagwatwatar H. Process and formulation variables in the preparation of wax microparticles by a melt dispersion technique. I. Oil-in-water technique for water-insoluble drugs. J Microencapsul 1992; 9: 89-98

[13] Bodmeier R., Wang J., Bhagwatwatar H. Process and formulation variables in the preparation of wax microparticles by a melt dispersion technique. 11. W/O/W multiple emulsion technique for water-soluble drugs. J Microencapsul 1992; 9: 99-107 
[14] Shinoda K., Saito H. The stability of O/W type emulsions as a function of temperature and the HLB of emulsifiers: the emulsification by PIT-method. J Colloid Interface Sci 1969; 30: 258-263

[15] Huynh N.T., Passirani C., Saulnier P., Benoit J.P. Lipid nanocapsules: a new platform for nanomedicine. Int J Pharm 2009; 379: 201-209

[16] Montenegro L., Campisi A., Sarpietro M.G., Carbone C., Acquaviva R., Raciti G., Puglisi G. In vitro evaluation of idebenone-loaded solid lipid nanoparticles for drug delivery to the brain. Drug Dev Ind Pharm 2011; 37: 737-746

[17] Hoar T.P., Schulman J.H. Transparent water in oil dispersions: the oleopathic hydromicelle. Nature 1943; 152: 102-103

[18] Attwood D. Microemulsions. in Colloidal drug delivery systems. Edited by Kreuter J. Marcel Dekker, New York 1994

[19] Kreilgaard M. Influence of microemulsions on cutaneous drug delivery. Adv Drug Deliv Rew 2002; 54: S77-S98

[20] Gasco M.R. Method for producing solid lipid microspheres having a narrow size distribution. US5250236 (1993)

[21] Morel S., Terreno E., Ugazio E., Aime S., Gasco M.R. NMR relaxometric investigations of solid lipid nanoparticles (SLN) containing gadolinium (III) complexes. Eur J Pharm Biopharm 1998; 45: 157-163

[22] Peira E., Marzola P., Podio V., Aime S., Sbarbati A., Gasco M.R. In vitro and in vivo study of solid lipid nanoparticles loaded with superparamagnetic iron oxide. J Drug Target 2003; 11: 19-24

[23] Mumper R.J., Jay M. Microemulsion as precursor to solid nanoparticles. US7153525 (2001)

[24] Koziara J.M., Oh J.J., Akers W.S., Ferraris S.P., Mumper R.J. Blood compatibility of cetyl alcohol/polysorbate-based nanoparticles. Pharm Res 2005; 22: 1821-1828

[25] Koziara J.M., Lockman P.R., Allen D.D., Mumper R.J. Paclitaxel nanoparticles for the potential treatment of brain tumors. J Control Release 2004; 99: 259-269

[26] Oyewumi M.O., Mumper R.J. Influence of formulation parameters on gadolinium entrapment and tumor cell uptake using folate-coated nanoparticles. Int J Pharm 2003; 251: 85-97

[27] Battaglia L., Trotta M., Cavalli R. Method for the preparation of solid micro and nanoparticles. WO2008149215 (2008)

[28] Battaglia L., Gallarate M., Cavalli R., Trotta M. Solid lipid nanoparticles produced through a coacervation method. J Microencapsul 2010; 27: 78-85 
[29] Bianco M.A., Gallarate M., Trotta M., Battaglia L. Amphotericin B loaded SLN prepared with the coacervation technique. J Drug Deliv Sci Tech, 2010; 20: 187-191

[30] Chirio D., Gallarate M., Peira E., Battaglia L., Serpe L., Trotta M. Formulation of curcumin-loaded solid lipid nanoparticles produced by fatty acids coacervation technique. J Microencapsul 2011; 28: 537-548

[31] Schubert M.A, Müller-Goymann. C.C. Solvent injection as a new approach for manufacturing lipid nanoparticles - evaluation of the method and process parameters. Eur J Pharm Biopharm 2003; 55: 125-131

[32] Hu F.Q., Yuan H., Zhang H., Fang M. Preparation of solid lipid nanoparticles with clobetasol propionate by a novel solvent diffusion method in aqueous system and physicochemical characterization. Int J Pharm 2002; 239: 121-128

[33] Siekmann B, Westesen K. Investigation on solid lipid nanoparticles prepared by precipitation in o/w emulsion. Eur J Pharm Biopharm 1996; 42:104-109

[34] Trotta M., Debernardi F., Caputo O. Preparation of solid lipid nanoparticles by a solvent emulsification-diffusion technique. Int J Pharm 2003; 257:153-160

[35] Garcia-Fuentes M., Torres D., Alonso M.J. Design of lipid nanoparticles for the oral delivery of hydrophilic macromolecules. Coll Surf B: Biointerf 2003; 27: 159-168

[36] Gallarate M., Trotta M., Battaglia L., Chirio D. Preparation of solid lipid nanoparticles from W/O/W emulsions: Preliminary studies on insulin encapsulation. J Microencaps 2009; 26: 394-402

[37] Berton A., Piel G., Evrard B. Powdered lipid nano and microparticles: production and applications. Recent Pat Drug Deliv Formul 2011; 5: 188-200

[38] Byrappa K., Ohara S., Adschiri T. Nanoparticles synthesis using supercritical fluid technology - towards biomedical applications. Adv Drug Deliv Rev 2008; 60: 299-327

[39] Ribeiro Dos Santos I., Richard J., Pech B., Thies C., Benoit J.P. Microencapsulation of protein particles within lipids using a novel supercritical fluid process Int J Pharm 2002; 242: 69-78

[40] Salmaso S., Elvassore N., Bertucco A., Caliceti P. Production of solid lipid submicron particles for protein delivery using a novel supercritical gas-assisted melting atomization process. J Pharm Sci 2009; 98: 640-649

[41] Vezzù K., Borin D., Bertucco A., Bersani S., Salmaso S., Caliceti P. Production of lipid microparticles containing bioactive molecules functionalised with PEG. J Supercritical Fluids 2010; 54: 328-334

[42] Bertucco A., Caliceti P., Elvassore N. Process for the production of nanoparticles. WO2007028421 (2007) 
[43] Chattopadhyay P., Shekunov B., Seitzinger J., Huff R. Particles from supercritical fluid extraction of emulsion. WO2004004862 (2004)

[44] Chattopadhyay P., Shekunov B., Yim D., Cipolla D., Boyd B. Farr S. Production of solid lipid nanoparticle suspensions using supercritical fluid extraction of emulsions (SFEE) for pulmonary delivery using the AERx system. Adv Drug Deliv Rev 2007; 6: 444-453

[45] Charcosset C., Fessi H. Novel method for preparing solid lipid nanoparticles using a membrane reactor. WO2007000531 (2007)

[46] Charcosset C., El-Harati A.A., Fessi H. Preparation of solid lipid nanoparticles using a membrane contactor. J Control Release 2005; 108: 112-120

[47] El-Harati A.A., Charcosset C., Fessi H. Influence of the formulation for solid lipid nanoparticles prepared with a membrane contactor. Pharm Dev Technol 2006; 11: 153-157

[48] Del Curto M.D., Chicco D., D'Antonio M., Ciolli V., Dannan H., D'Urso S., Neuteboom B., Pompili S., Schiesaro S., Esposito P. Lipid microparticles as sustained release system for a GnRH antagonist (Antide). J Control Release 2003; 89: 297-310

[49] Del Curto M.D., Chicco D., Esposito P. Lipid microparticles by cryogenic micronization US2004091522 (2004)

[50] Killeen M.J. Spray drying and spray congealing of pharmaceuticals. In Encyclopedia of Pharmaceutical Technology. Edited by Swarbrick J. Boylan JC 2000

[51] Pilcer G., Amighi K. Formulation strategy and use of excipients in pulmonary drug delivery. Int J Pharm 2010; 392:1-19

[52] Sebti T., Amighi K. Preparation and in vitro evaluation of lipidic carriers and fillers for inhalation. Eur J Pharm Biopharm 2006; 63: 51-58

[53] Amighi K., Sebti T. Solid lipid particules as pharmaceutically acceptable fillers or carriers for inhalation. WO2006066367 (2006)

[54] Trotta M., Cavalli R., Trotta C., Bussano R., Costa L. Electrospray technique for solid lipid-based particle production. Drug Dev Ind Pharm 2010; 36: 431-438

[55] Bussano R., Chirio D., Costa L., Turci F., Trotta M. Preparation and characterization of insulin loaded lipid-based microspheres generated by electrospray. J Disper Sci Technol 2011; 32: 1524-1530

[56] Rodriguez L., Cavallari C., Motta G. Apparatus and method for preparing solid forms with controlled release of the active ingredient. WO 9603979 (1996)

[57] Passerini N., Qi S., Albertini B., Grassi M., Rodriguez L., Craig D.Q. Solid lipid microparticles produced by spray congealing: influence of the atomizer on microparti- 
cle characteristics and mathematical modeling of the drug release. J Pharm Sci 2010; 99: 916-931

[58] Rodriguez L., Passerini N., Cavallari C., Cini M., Sancin P., Fini A. Description and preliminary evaluation of a new ultrasonic atomizer for spray-congealing processes. Int J Pharm 1999; 183: 133-143

[59] Akiyama Y., Yoshioka M., Horibe H., Hirai S., Kitamori N., Toguchi H. Novel oral controlled-release microspheres using polyglycerol esters of fatty acids. J Control Release 1993; 26: 1-10 
